\title{
The Utility of Short-Interval Repeat Computed Tomography Angiogram After Blunt Cerebrovascular Injury in Adults
}

\author{
Zaid Aljuboori $^{1}$, Kimberly Meyer ${ }^{2}$, Dale Ding ${ }^{1}$ \\ 1. Neurological Surgery, University of Louisville School of Medicine, Louisville, USA 2. Neurological Surgery, University \\ of Louisville, Louisville, USA
}

Corresponding author: Zaid Aljuboori, zaid.aljuboori@yahoo.com

\section{Abstract \\ Introduction}

Blunt cerebrovascular injury (BCVI) can lead to thromboembolic events. The necessity of short-interval noninvasive vascular imaging after the initial diagnosis is controversial. This retrospective cohort assesses the utility of short-interval computed tomography angiography (CTA) after an initial diagnosis of BCVI.

\section{Methods}

We retrospectively reviewed patients with BCVI managed at our institution from 2016 to 2019 who underwent a short-interval (one to three weeks) repeat CTA after initial diagnosis. We excluded patients with age $<18$ years, penetrating injury, and previous neck irradiation. We collected baseline data and performed logistic regression to identify predictors of BCVI imaging outcomes.

\section{Results}

The study cohort comprised 38 patients with a mean age of 45 years with $68 \%$ males. Motor vehicle crash (MVC) was the most common mechanism of $79 \%$ injury. Unilateral vertebral artery (VA) was the most common vessel that is $66 \%$ injured, and grade I $36 \%$ was the most common dissection on initial CTA. Grades III and IV dissection 33\% were the most common in the short-interval CTA. Shift analysis showed a significant improvement in Biffl grades I on the short-interval CTA $(p=0.0001)$. Antiplatelet therapy or anticoagulation (AC) was administered to $82 \%$ of patients after the initial diagnosis. The rates of early $(<2$ weeks) and delayed (two weeks to three months) ischemia were $5 \%$ and $0 \%$, respectively, and endovascular stenting was performed in $8 \%$.

\section{Conclusion}

BCVI grades I and II are more frequent than high-grade injuries. Short-interval non-invasive vascular imaging can detect changes of BCVI which can affect the management paradigm. It also can select patients

Received 07/28/2020 Review began $07 / 31 / 2020$ Review ended 08/16/2020 Published 08/23/2020

() Copyright 2020 Aljuboori et al. This is an open access article distributed under the terms of the Creative Commons Attribution License CC-BY 4.0., which permits unrestricted use, distribution, and reproduction in any medium, provided the original author and source are credited. who will benefit from endovascular intervention and avoid stroke. Besides, the short-interval non-invasive vascular imaging will not incur additional cost or increase exposure to radiation.

Categories: Emergency Medicine, Neurosurgery, Trauma

Keywords: trauma, dissection, vascular, vertebral, carotid

\section{Introduction}

Blunt cerebrovascular injury (BCVI) is an injury of the carotid and/or vertebral arteries (VAs) due to nonpenetrating trauma. It is usually associated with fractures of the skull base, cervical spine, or first rib. Biffl et al. described the most commonly used classification scheme for BVCI [1]. The trauma can cause an intimal tear and, in some cases, leads to pseudoaneurysm formation [2-5]. Intimal injury can lead to thrombosis and vessel occlusion or release of emboli, and both can lead to devastating stroke [6-8]. Antiplatelet or anticoagulation (AC) is usually used to prevent such complications, and in some cases, endovascular intervention is needed [9].

There is controversy concerning the need for short-interval follow-up vascular imaging (e.g., computed tomography angiography, CTA) after the initial diagnosis. Some authors suggested that it can clarify the diagnosis where the initial CTA was confounded by vessel spasm [6]. Others suggested that it may not be beneficial in high-grade BCVI, as most injuries do not resolve. Also, it may incur an unnecessary additional cost and radiation [10]. We report our analysis on the utility of short-interval CTA after an initial diagnosis of BCVI.

\section{Materials And Methods}




\section{Cureus}

We retrospectively reviewed consecutive patients with BCVI managed at the University of Louisville from 2016 to 2019 who underwent short-interval (one to three weeks) CTA after initial diagnosis. The exclusion criteria were age $<18$ years, penetrating injury, a diagnosis of BCVI with no short-interval CTA, and previous neck irradiation. We collected the patients' demographics, mechanism of injury, presence of cervical spine or first rib fractures, grade of dissection on initial and repeat CTA, use of antiplatelet or AC, the incidence of stroke, and need for vascular intervention.

\section{Statistical analysis}

We used the mean with standard deviation to summarize continuous variables; counts and percentages summarized categorical variables. We used Chi-square to compare categorical outcomes and the ordered logistic regression for ordinal outcomes. Multinomial logistic regression was used to identify predictors of imaging outcomes of vascular injury. All tests were two-sided with a significance level of 0.05 . Statistical data analysis was performed in Stata 13 (StataCorp, College Station, USA).

\section{Results}

The total number of patients with a diagnosis of BCVI was 205, but only 38 (15\%) had short-interval CTA (because of differences in the management strategy of BCVI among neurosurgeons at our institution). For patients $(\mathrm{N}=38)$ who had a short-interval CTA, the mean age was 45 years for males $(68 \%)$. MVC was the most common mechanism of injury (79\%), and $89 \%$ of patients had cervical spine fractures (Table 1 ). Unilateral VA was the most common vessel (66\%) injured and grade I (36\%) was the most common dissection on initial CTA. Grades III and IV dissection (33\%) were the most common on the short-interval repeat CTA (Table 2). Shift analysis showed a significant improvement in Biffl grades I on the short-interval repeat CTA $(\mathrm{p}=0.0001$, Figure 1$)$. In addition, Biffl grade I injuries were more likely to improve (relative risk ratio $[R R R]=$ 3.6, CI 95\% (1.02-13.1), $\mathrm{p}=0.04)$, whereas grade IV injuries were more likely to be stable ( $\mathrm{RRR}=33, \mathrm{CI} 95 \%$ (2.9-374), $\mathrm{p}=0.005$ ). Antiplatelet therapy or AC was administered to $82 \%$ of patients after the initial diagnosis. Ten BCVIs (26\%) were resolved on repeat imaging (Table 3). The rates of early ( $<2$ weeks) and delayed ( 2 weeks to 3 months) ischemia were $5 \%$ and $0 \%$, respectively, and endovascular stenting was performed in $8 \%$ of patients.

\begin{tabular}{|c|c|c|}
\hline Variable & & Percentage \\
\hline Gender & Males & $68 \%$ \\
\hline \multirow{2}{*}{ Mechanism of injury } & Fall & $21 \%$ \\
\hline & MVC & $79 \%$ \\
\hline Cervical spine fractures & & $89 \%$ \\
\hline First rib fractures & & $16 \%$ \\
\hline Early stroke & & $5 \%$ \\
\hline Delayed stroke & & $0 \%$ \\
\hline Endovascular intervention & & $8 \%$ \\
\hline Received ASA or AC between first and second CTA & & $82 \%$ \\
\hline Received ASA or AC after second CTA & & $82 \%$ \\
\hline
\end{tabular}

\section{TABLE 1: Patients demographics}

AC: anticoagulation, ASA: aspirin, CTA: computed tomography angiogram, MVC: motor vehicle crash, FFH: fall from height. 


\section{Cureus}

\begin{tabular}{|c|c|c|}
\hline Variable & Number of dissections & Percentage \\
\hline VA (unilateral) & 25 & $66 \%$ \\
\hline VA (bilateral) & 4 & $11 \%$ \\
\hline Total VA & 33 & $70 \%$ \\
\hline ICA (unilateral) & 6 & $16 \%$ \\
\hline ICA (bilateral) & 4 & $11 \%$ \\
\hline Total ICA & 14 & $30 \%$ \\
\hline
\end{tabular}

\section{TABLE 2: Percentage of vascular injuries}

VA: vertebral artery, ICA: internal carotid artery.

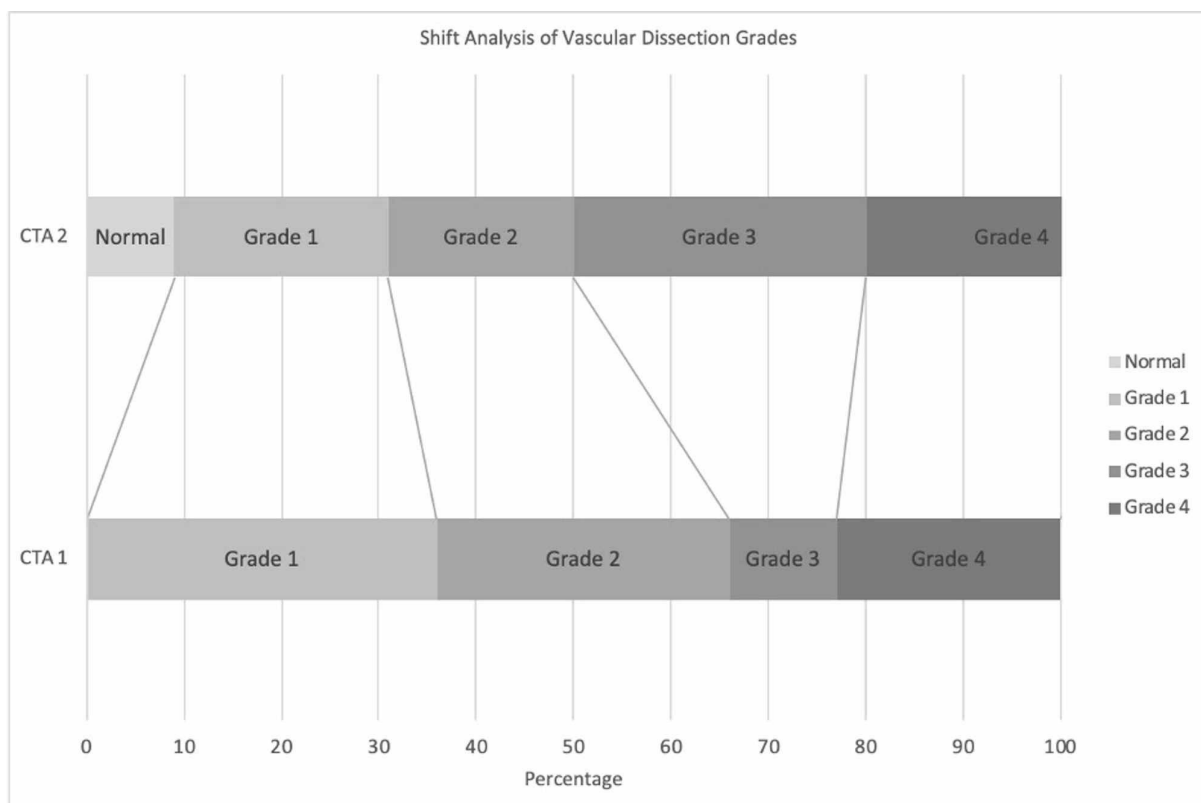

FIGURE 1: A bar graph that shows the shift analysis of vascular dissection grade on repeat (second CTA) imaging

CTA: computed tomography angiogram. 


\section{Cureus}

\begin{tabular}{|c|c|c|}
\hline Number of patients & Second CTA & Third CTA \\
\hline Total & 38 & 16 \\
\hline Normalized & $9(24 \%)$ & $1(6 \%)$ \\
\hline Improved & $2(5 \%)$ & $6(38 \%)$ \\
\hline Stabilized & 14 (37\%) & $9(56 \%)$ \\
\hline Worsened & 13 (34\%) & $0 \%$ \\
\hline \multicolumn{3}{|c|}{$\begin{array}{l}\text { TABLE 3: Imaging outcomes of vascular injuries on second and third CTA } \\
\text { CTA: computed tomography angiogram. Normalized = normal findings on CTA. Improved = increased flow, increased diameter, smaller } \\
\text { pseudoaneurysm, etc. Stable = similar characteristics to previous imaging. Worsened = decreased flow, decreased diameter, larger } \\
\text { pseudoaneurysm, etc. }\end{array}$} \\
\hline
\end{tabular}

\section{Discussion}

BCVI are managed medically with antiplatelet or anticoagulants, with endovascular stenting reserved for symptomatic or worsening stenosis, and the severity of the injury correlates with the risk of stroke [8,9]. In this study, the short-interval (one to three weeks) repeat CTA revealed that (65\%) of grade I dissection had resolved, and a sizable percentage of grade II (57\%) dissection had progressed to grades III and IV. These findings echo what Wagenaar et al. reported as they showed that grades I and II had a higher chance for improvement (56\% and 18\%), respectively, compared to grades III and IV ( $8 \%$ and $2 \%$ ), respectively [10]. Three patients (8\%) with ICA dissection needed an early (within two weeks of injury) endovascular stenting because of a worsened dissection in one case and ischemic complications in the other two. Notably, all three patients were on ASA. In retrospect, the two patients who had ischemic complications could have benefited from an earlier ( $<10$ days) repeat CTA as it might have led to earlier detection of the worsening of the ICA dissection and prevented the ischemic complications. The delayed CTA (8-16 weeks) showed only $6 \%$ of patients had a resolution of their dissections with the remaining having either improved to a lower grade (38\%) or remained stable (56\%). Notably, none of the patients required a delayed endovascular intervention, and there were no delayed strokes (two weeks to three months) within the cohort. Eighty-two percent of patients were treated with ASA or oral AC, while the remaining (18\%) did not receive during the early phase of injury because of planned surgical intervention during hospitalization.

The short-interval CTA is beneficial to detect changes in the grade of the dissection as we showed that most BCVI resolved or worsen in the early phase of the injury. It will also enable the treating physician to manage any worsening hastily, especially for patients who need endovascular intervention, which can prevent the devastation caused by a stroke. For patients with resolved dissection, AC or ASA can be stopped. From a cost-saving perspective, the resolution of the dissection on the short-interval CTA will obviate the need for a delayed CTA, which will not incur additional cost or increase exposure to radiation for this subgroup of patients. Patients with persistent dissection on the short-interval CTA will need further observation with vascular imaging. Although this will add cost and radiation exposure, the detection and treatment of any injury progression on the short-interval CTA can prevent the disability and financial consequences of a stroke. Therefore, we recommend a short-interval CTA within one to three weeks of the initial diagnosis or even earlier in patients with ICA dissection.

\section{Limitations}

One should keep in mind that our study is retrospective with relatively small sample size and the potential for selection bias. Also, interobserver variability can exist as different radiologists read different imaging studies. Therefore, additional studies are necessary to clarify the role of short-interval non-invasive vascular imaging in the management of BCVI.

\section{Conclusions}

Low-grade BCVI is more frequent than high-grade injuries. Short-interval non-invasive vascular imaging can identify changes in BCVI which can alter the management plan. It also can identify patients who will benefit from endovascular intervention and prevent stroke. Besides, the short-interval non-invasive vascular imaging will not incur additional cost or increase exposure to radiation.

\section{Additional Information}

\section{Disclosures}

Human subjects: Consent was obtained by all participants in this study. Animal subjects: All authors have 
confirmed that this study did not involve animal subjects or tissue. Conflicts of interest: In compliance with the ICMJE uniform disclosure form, all authors declare the following: Payment/services info: All authors have declared that no financial support was received from any organization for the submitted work. Financial relationships: All authors have declared that they have no financial relationships at present or within the previous three years with any organizations that might have an interest in the submitted work. Other relationships: All authors have declared that there are no other relationships or activities that could appear to have influenced the submitted work.

\section{References}

1. Biffl WL, Moore EE, Offner PJ, Brega KE, Franciose RJ, Burch JM: Blunt carotid arterial injuries: implications of a new grading scale. J Trauma. 1999, 47:845-853. 10.1097/00005373-199911000-00004

2. Biffl WL, Moore EE, Offner PJ, Burch JM: Blunt carotid and vertebral arterial injuries. World J Surg. 2001, 25:1036-1043. 10.1007/s00268-001-0056-X

3. Durand D, Wu X, Kalra VB, Abbed KM, Malhotra A: Predictors of vertebral artery injury in isolated C2 fractures based on fracture morphology using CT angiography. Spine. 2015, 40:713-718. $10.1097 /$ BRS. 0000000000000893

4. Kopelman TR, Leeds S, Berardoni NE, et al.: Incidence of blunt cerebrovascular injury in low-risk cervical spine fractures. Am J Surg. 2011, 202:684-688. 10.1016/j.amjsurg.2011.06.033

5. McKinney A, Ott F, Short J, McKinney Z, Truwit C: Angiographic frequency of blunt cerebrovascular injury in patients with carotid canal or vertebral foramen fractures on multidetector CT. Eur J Radiol. 2007, 62:385-393. 10.1016/j.ejrad.2007.01.008

6. Crawford JD, Allan KM, Patel KU, et al.: The natural history of indeterminate blunt cerebrovascular injury . JAMA Surg. 2015, 150:841-847. 10.1001/jamasurg.2015.1692

7. Scott WW, Sharp S, Figueroa SA, Eastman AL, Hatchette CV, Madden CJ, Rickert KL: Clinical and radiographic outcomes following traumatic Grade 3 and 4 carotid artery injuries: a 10-year retrospective analysis from a Level 1 trauma center. The Parkland Carotid and Vertebral Artery Injury Survey. J Neurosurg. 2015, 122:610-615. 10.3171/2014.10.JNS14875

8. Weber CD, Lefering R, Kobbe P, et al.: Blunt cerebrovascular artery injury and stroke in severely injured patients: an international multicenter analysis. World J Surg. 2018, 42:2043-2053. 10.1007/s00268-0174408-6

9. Mei Q, Sui M, Xiao W, Sun Z, Bai R, Huang C, Hou L: Individualized endovascular treatment of high-grade traumatic vertebral artery injury. Acta Neurochir. 2014, 156:1781-1788. 10.1007/s00701-014-2074-0

10. Wagenaar AE, Burlew CC, Biffl WL, et al.: Early repeat imaging is not warranted for high-grade blunt cerebrovascular injuries. J Trauma Acute Care Surg. 2014, 77:540-545. 10.1097/TA.0000000000000418 